\title{
INVESTIGATION OF THE AIR QUALITY CHANGE EFFECT ON GNSS SIGNALS
}

\author{
G. Gurbuz ${ }^{\text {a, } *, \text { K. S. Gormus }}{ }^{\text {a }}$ U. Altan ${ }^{\text {a }}$ \\ ${ }^{a}$ Bulent Ecevit University, Engineering Faculty, Department of Geomatics Engineering, 67100, Zonguldak, Turkey \\ (gokhan.gurbuz@beun.edu.tr, umutaltann@gmail.com, sedargormus@ hotmail.com)
}

KEY WORDS: Air pollution, GNSS, Troposphere, Zenit Wet Delay, $\mathrm{PM}_{10}$

\begin{abstract}
:
Air pollution is the most important environmental problem in Zonguldak city center. Since bituminous coal is used for domestic heating in houses and generating electricity in thermal power plants, particulate matter $\left(\mathrm{PM}_{10}\right)$ is the leading air pollutant. Previous studies have shown that the water vapor in the troposphere is responsible for the tropospheric zenith delay in Global Navigation Satellite System (GNSS) measurements. In this study, data obtained from the ZONG GNSS station from Türkiye Ulusal Sabit GNSS Ağı (TUSAGA-Active network) in the central district of Zonguldak province, processed with GIPSY-OASIS II and GAMIT/GlobK software using the VMF1 mapping function, which is developed previously and considered to be the most accurate model. The resulting values were examined separately in terms of software. The meteorological parameters obtained from the Turkish State Meteorological Service and the air pollution values obtained from the Ministry of Environment and Urban Planning were analyzed and the zenith delay values were compared. When wet zenith delays of different days with different amounts of PM10 concentrations were examined in succession and under the same meteorological conditions, differences in the range of 20-40 mm on ZTD were observed.
\end{abstract}

\section{INTRODUCTION}

Air pollution can be nature based or human-induced. For example, natural events such as forest fires and lightning cause the atmospheric nitrogen ratio to increase. From a human perspective, fires that are occurred whatever the reason, smokes which are emitted from factory and airplanes flights through the atmosphere, and gases from the exhausts of vehicles cause the air to interfere with the abundant amounts of gases such as carbon monoxide, sulfur dioxide, and nitric acid. As a result, gases released into the atmosphere cause air pollution by changing the gas concentration in the air. According to the United States Environmental Protection Agency standards, air pollution is determined by a number of components such as ozone (O3), carbon monoxide $(\mathrm{CO})$, sulfur dioxide ( $\mathrm{SO} 2)$, nitrogen oxide (NO), liquids and particulates in the air (Robert-Lambach, 2010).

In practice, however, pollution is generally determined by the amount of airborne solid particles (PM) and sulfur dioxide. These small particles are formed by the atmospheric mixing of solid and liquid components, such as exhaust gases, forest fires, cigarette smoke, road dust, windy soil, volcanic gases and sea evaporation. Particles can be named coarse (diameters between $2.5 \mu \mathrm{m}$ and 10 $\mu \mathrm{m}$ ), thin (diameters smaller than $2.5 \mu \mathrm{m}$ ) and very thin (diameters smaller than $0.1 \mu \mathrm{m}$ ) according to their diameter (Seinfeld and Pandis, 2006).

In the last decades, the GNSS has been widely used in navigation, positioning, timing and related sciences. However, GNSS observations are subject to several sources of error, such as clock biases, multi-path delay, and ionospheric and tropospheric delays. Particularly, the tropospheric delay significantly affects the GNSS signals and causes errors of several meters in positioning. Since the GNSS signal is sensitive to the tropospheric refractive index, which is dependent on the pressure, temperature, and moisture, GNSS can be used for sensing these properties in the troposphere, e.g., tropospheric water vapor (Jin and Luo, 2009; Gurbuz, 2015). The total zenith tropospheric delay (ZTD) is the difference between the optical and geometric path in the zenith between the GNSS satellite and the receiver over the station, including the dry zenith delay (ZHD) and the zenith wet delay (ZWD) (Gurbuz, 2016). The first one depends on the atmospheric pressure, which can be computed with the pressure value of the station directly and accurately, and the second one is computed by subtracting ZHD from ZTD.

In this study, effects of particulate matters on zenith tropospheric delay estimated with GNSS observations are investigated. In order to achieve results, parameters which affect GNSS estimated ZTD such as temperature, pressure, humidity is obtained and compared on consecutive days for same GNSS station. Finally, days which have same atmospheric conditions but different $\mathrm{PM}_{10}$ concentrations are found at the station called ZONG from TUSAGA-Active network which is located at Zonguldak city in Turkey.

\section{DATA AND METHOD}

The Central District within the Zonguldak province borders in the Western Black Sea region was designated as the study area. The land structure of the region is steep and sloping as it is in the whole Black Sea Region. The city center is at sea level and surrounded by hills. In this region industrial gases released due to gas emissions caused by humans. The main cause of the gas release caused by humans in the study area is the use of carbon tetrachloride as a fuel source in the region, especially in the winter months (Zeydan, 2014).

Even if the use of natural gas is begun in most districts of the central province starting from 2015, and the amount of air pollution decreases gradually. Due to the settlements that have not yet been used for natural gas, air pollution is not reduced to the standard values exactly. Even in clean air, visibility is limited to a few hundred kilometers because of the light scattering

\footnotetext{
* Corresponding author
} 
properties of gases (Rayleigh scattering). If the air is dirty, the visibility distance is reduced due to the emission of light and absorption of gases and particles (Zeydan, 2014).

The decrease in visibility due to particulate matter is seen in the photographs taken at the port of Zonguldak in Figure 1 and Figure 2. Figure 1 shows the photo was taken at 10:00 am on November 28, 2016, and Figure 2 shows the photo was taken at 6:00 pm on September 6, 2016. The $\mathrm{PM}_{10}$ concentration at the time of photographing in Figure 1 is $191 \mu \mathrm{g} / \mathrm{m}^{3}$ and the $\mathrm{PM}_{10}$ concentration of Figure 2 is $40 \mu \mathrm{g} / \mathrm{m}^{3}$ according to the value obtained from the website of the Ministry of Environment and Urban Planning.

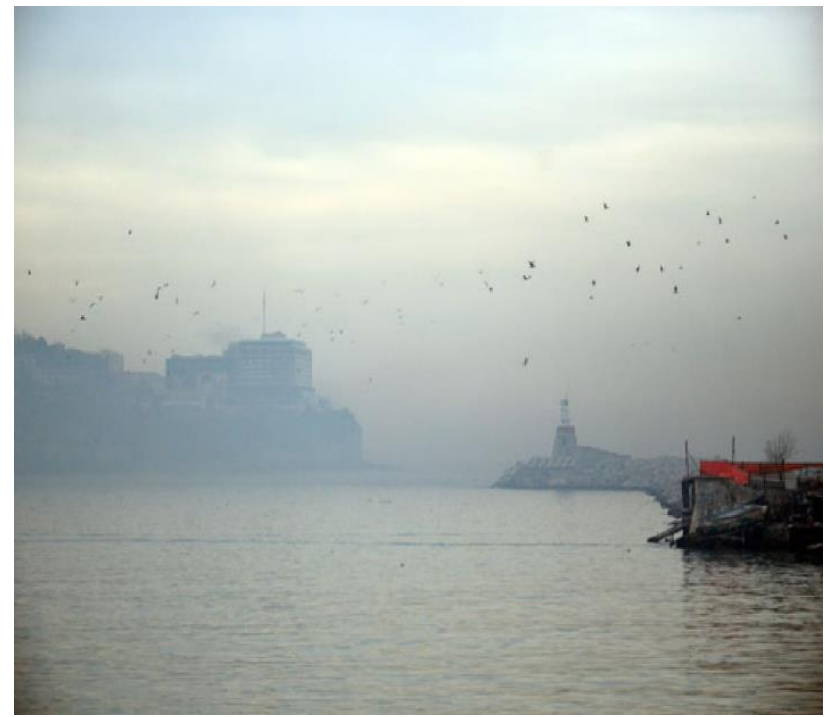

Figure 1. Low visibility range in Zonguldak $\left(\mathrm{PM}_{10}=191 \mu \mathrm{g} / \mathrm{m}^{3}\right)$.

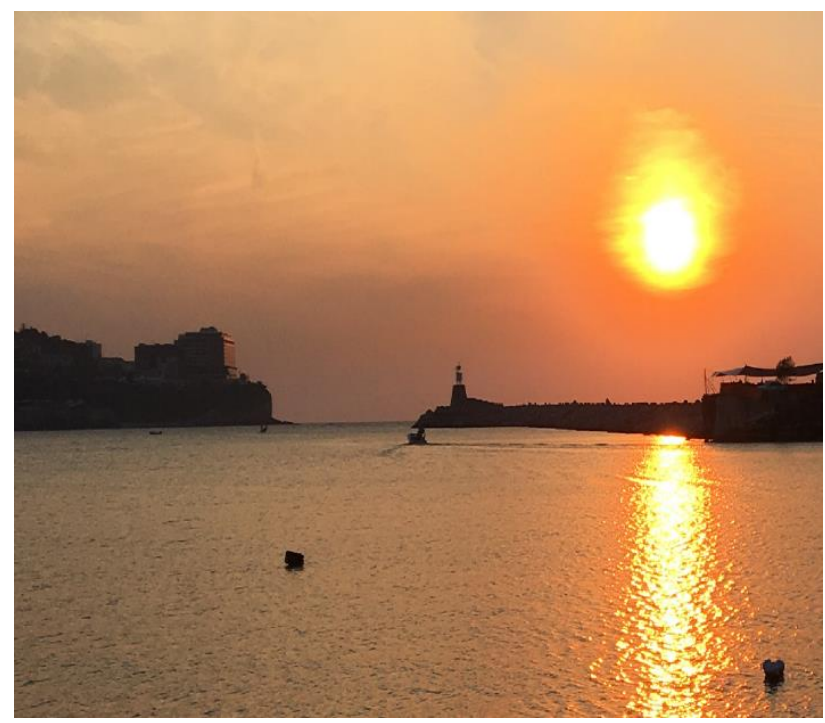

Figure 2. Normal visibility range in Zonguldak $\left(\mathrm{PM}_{10}=40 \mu \mathrm{g} / \mathrm{m}^{3}\right)$.

Measurements for determining the quality of air in the provincial and district centers are obtained from Air Quality Monitoring Stations belong to the Ministry of Environment and Urban Planning. The PM 10 concentrations measured in the Zonguldak central district for 2014 and 2015 are shown in Figure 3.

Time series were created using the daily average for $\mathrm{PM}_{10}$ measurements made in 2014 and 2015 from the Zonguldak Air
Quality Monitoring Station. The reason for the anomalies in the $\mathrm{PM}_{10}$ data in Figure 3 is the intense consumption of coal for heating purposes, especially in the winter months. The absence of coal consumption during the summer shows the decrease in $\mathrm{PM}_{10}$ values.

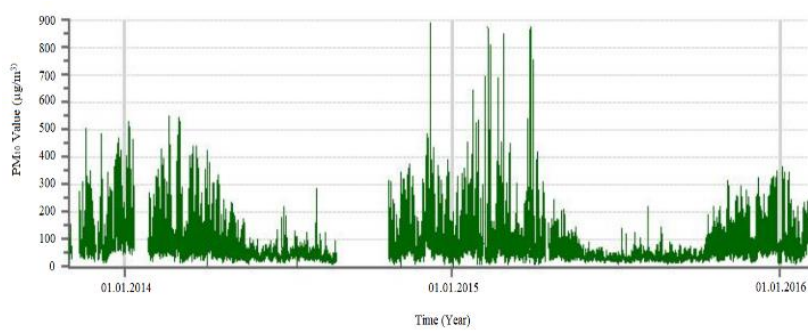

Figure 3. $\mathrm{PM}_{10}$ time series of Zonguldak for 2014-2016.

In this study, data from ZONG station which belongs to the TUSAGA-Active network were used. The reason for choosing this station is its proximity to air quality measurement stations and meteorological sensors located in the central district of Zonguldak. In order to evaluate this data with GAMIT/GlobK software (Herring et al, 2010), stations from IGS (International GNSS Service) and EPN (EUREF Permanent Network) networks are used (Figure 4).

Observations for these GNSS stations have been obtained from the website of the Bundesamt für Kartographie und Geodäsie (BKG). In addition, temperature, pressure, humidity and precipitation data for the time interval assessed by the Turkish General Directorate of Meteorology are obtained for the comparison of wet zenith delay values.

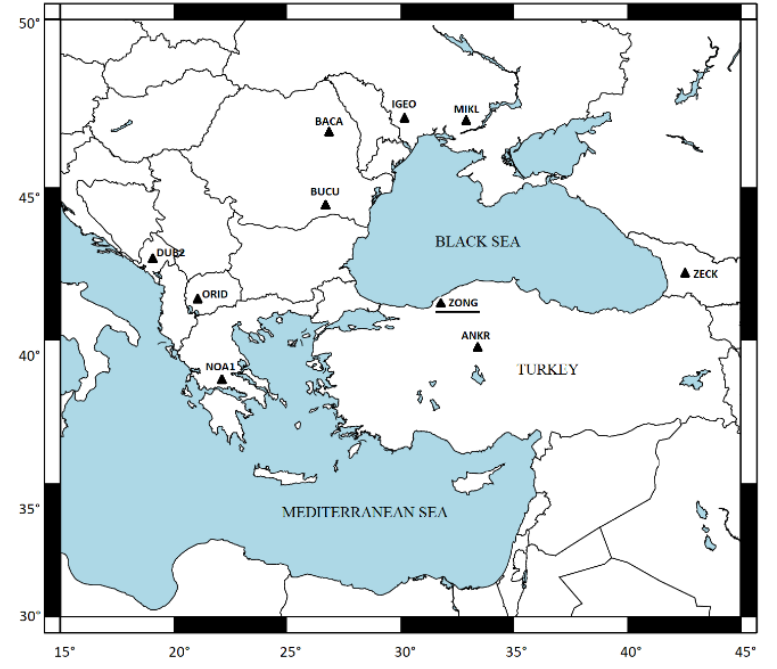

Figure 4. $\mathrm{PM}_{10}$ time series of Zonguldak.

In this study, data obtained from ZONG station are evaluated with the aid of GAMIT/ GlobK and GIPSY-OASIS II academic GNSS software using parameters given in Table 1. 


\begin{tabular}{|l|c|c|}
\hline Parameters & GAMIT/GLOBK & GIPSY-OASIS II \\
\hline Experiment Type & DD & PPP \\
\hline Estimation & Hourly & Hourly \\
\hline Zenith Constraints & 0,50 & 0.50 \\
\hline Elevation Angle & $10^{\circ}$ & $10^{\circ}$ \\
\hline Loading Effects & $63($ all) & None \\
\hline Output & ZTD, ZWD & only ZWD \\
\hline Dry \& Wet MF & VMF1 & VMF1 \\
\hline Orbit & IGS Final & JPL Final \\
\hline Ionosphere & Iono-free & IONEX \\
\hline HOI & Included & Included \\
\hline
\end{tabular}

Table 1. Parameters for GNSS data processing.

In Table 1, the Experiment type describes the solution strategy to be used for evaluation, Zenith Constraints is the constraints to be applied to the zenith delay estimation, and the Dry \& Wet MF is the mapping function to estimate zenith delays (Boehm, 2006) In addition, in the Ionospheric solution, GAMIT/GlobK software uses ionospheric independent phase combination, but GIPSYOASIS II software (Gregorius, 1996) uses IONEX file for ionospheric delay. Precise orbit products are used for both solutions.

The results of the 2015 ZTD estimations from GAMIT/GlobK and GIPSY-OASIS II software were given in Figure 5. A maximum of $11 \mathrm{~mm}$, a minimum of $0.1 \mathrm{~mm}$ difference and an average of $5 \mathrm{~mm}$ difference between the total zenith delay values were determined in the evaluations made with two different academic GNSS software. Since the differences obtained from the software comparison are very low, the remaining evaluations were made only with the GIPSY-OASIS II academic GNSS evaluation software.

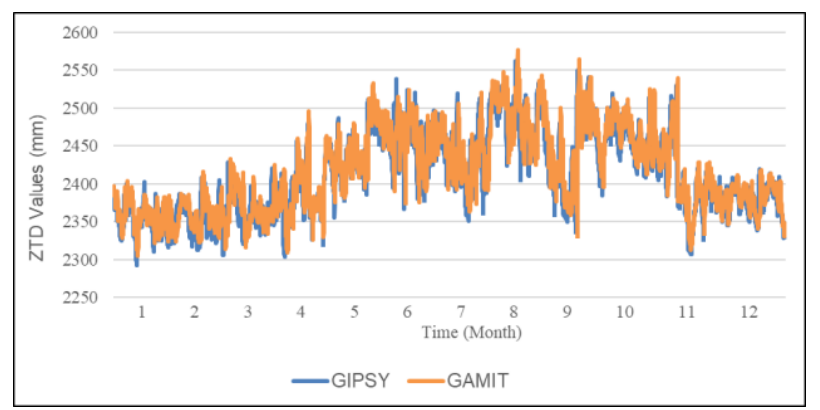

Figure 5. ZTD Estimations with GAMIT/ GlobK and GIPSYOASIS II software.

\section{ANALYSIS AND RESULTS}

In this study, hourly changes of $\mathrm{PM}_{10}$ values were examined at the central district of Zonguldak province, which was selected as test zone between 1 January 2014 and 31 December 2015. The temperature, pressure and humidity values affecting the wet zenith delay were obtained from the General Directorate of Meteorology and wet zenith delays in the days with high $\mathrm{PM}_{10}$ values were examined. In Table 2 some examples are given in which the meteorological parameters are same but the difference in $\mathrm{PM}_{10}$ amounts is large. The effect of the $\mathrm{PM}_{10}$ amount was investigated by comparing wet zenith delays of given days. After 2016, since the use of coal slowly decreases, which affects the $\mathrm{PM}_{10}$ concentrations in Zonguldak, the data for 2014 and 2015 were used in the study. The reason behind the dates chosen from November, December, January, and February is that coal consumption is high in winter months. The reason why selected days are close to each other is to examine the ZWD values in days with approximately the same meteorological parameters but different $\mathrm{PM}_{10}$ values. In addition to the exhaust gas, thermal power plants and coal consumption in industrial areas can be considered as $\mathrm{PM}_{10}$ sources. In central Zonguldak city, central heating boilers used during the winter months were supported by coal twice in the midday and evening such as in Figure 6 . However, in summer periods $\mathrm{PM}_{10}$ concentrations decrease drastically as the coal usage in the city drops (Figure 7).

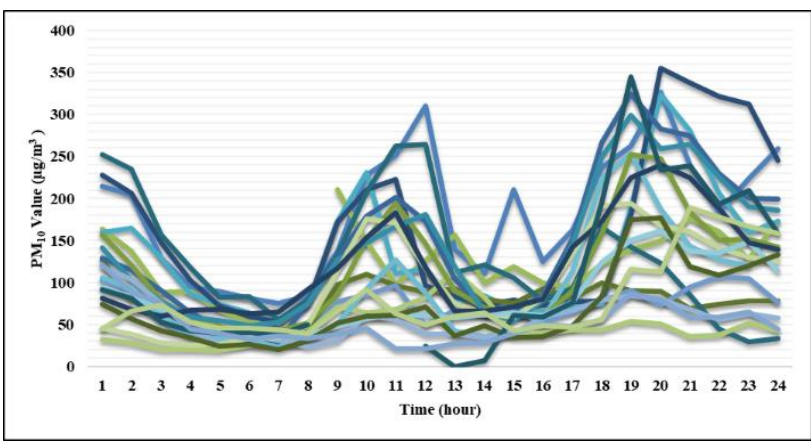

Figure 6. PM $\mathrm{PM}_{10}$ values of Zonguldak at 2014 winter period.

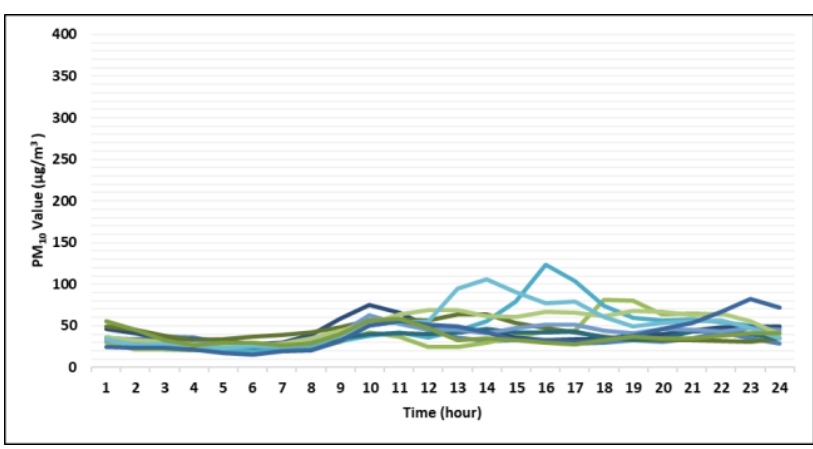

Figure 7. $\mathrm{PM}_{10}$ values of Zonguldak at 2015 summer period.

In Table 2 several examples are given in with the same meteorological parameters but the different $\mathrm{PM}_{10}$ values. The effect of the $\mathrm{PM}_{10}$ amount was investigated by comparing the wet zenith delays of these days. When the data are analyzed, it is seen that the ZWD values are increasing at noon and generally increased at the evening.

\begin{tabular}{|r|c|c|c|c|}
\hline \multicolumn{1}{|c|}{ Time } & $\begin{array}{c}\text { Temperatur } \\
\mathrm{e} \\
\left({ }^{\circ} \mathrm{C}\right)\end{array}$ & $\begin{array}{c}\text { Pressur } \\
\mathrm{e} \\
(\mathrm{hPa})\end{array}$ & $\begin{array}{c}\text { Humidit } \\
\mathrm{y} \\
(\%)\end{array}$ & $\begin{array}{c}\mathrm{PM}_{10} \\
{\left[\mu \mathrm{g} / \mathrm{m}^{3}\right.} \\
]\end{array}$ \\
\hline $\begin{array}{r}15 / 01 / 201 \\
5\end{array}$ & 5.3 & 1002.26 & 88 & 182.5 \\
\hline $\begin{array}{r}16 / 01 / 201 \\
5\end{array}$ & 5.3 & 1009.24 & 81.2 & 124.2 \\
\hline $\begin{array}{r}06 / 02 / 201 \\
4\end{array}$ & 3.5 & 1004.30 & 85.8 & 133.6 \\
\hline $\begin{array}{r}07 / 02 / 201 \\
4\end{array}$ & 3.5 & 1004 & 84.4 & 160.9 \\
\hline $\begin{array}{r}05 / 12 / 201 \\
5\end{array}$ & 6.8 & 1017.32 & 66.0 & 94.0 \\
\hline $\begin{array}{r}07 / 12 / 201 \\
5\end{array}$ & 5.2 & 1020.05 & 66.8 & 146.7 \\
\hline $\begin{array}{r}19 / 12 / 201 \\
5\end{array}$ & 5.5 & 1015.67 & 85.5 & 117.9 \\
\hline $21 / 12 / 201$ & 4.9 & 1010.88 & 73.0 & 147.4 \\
5 & & & & \\
\hline $\begin{array}{r}22 / 11 / 201 \\
5\end{array}$ & 19.4 & 994.53 & 39.7 & 57.0 \\
\hline
\end{tabular}




\begin{tabular}{|r|c|c|c|c|}
\hline $\begin{array}{r}23 / 11 / 201 \\
5\end{array}$ & 20.0 & 1004.98 & 33.0 & 99.1 \\
\hline $\begin{array}{r}11 / 11 / 201 \\
5\end{array}$ & 15.0 & 1009.35 & 79.5 & 82.3 \\
\hline $\begin{array}{r}12 / 11 / 201 \\
5\end{array}$ & 13.8 & 1002.94 & 76.3 & 120.7 \\
\hline $\begin{array}{r}03 / 11 / 201 \\
4\end{array}$ & 9.7 & 1006.63 & 90.9 & 69.6 \\
\hline $\begin{array}{r}04 / 11 / 201 \\
4\end{array}$ & 9.2 & 1011.09 & 89.0 & 106.6 \\
\hline $\begin{array}{r}29 / 10 / 201 \\
4\end{array}$ & 14.7 & 999.03 & 80.7 & 51.4 \\
\hline $\begin{array}{r}30 / 10 / 201 \\
4\end{array}$ & 14.6 & 1003.15 & 79.7 & 80.2 \\
\hline
\end{tabular}

Table 2. Meteorological parameters of given days for PM10 comparison.

The reason for this increase compared with $\mathrm{PM}_{10}$ values. While the days indicated in Table 2 are examples of consecutive days with same meteorological conditions. In Table 2 given values are average values during the day. A difference of $50 \mu \mathrm{g} / \mathrm{m}^{3}$ was observed at the average $\mathrm{PM}_{10}$ amount on 05-07 December 2015, whereas an average difference of $30 \mathrm{~mm}$ was calculated for the wet zenith delay values. Figure 8 shows ZWD values on 05-07 December 2015.

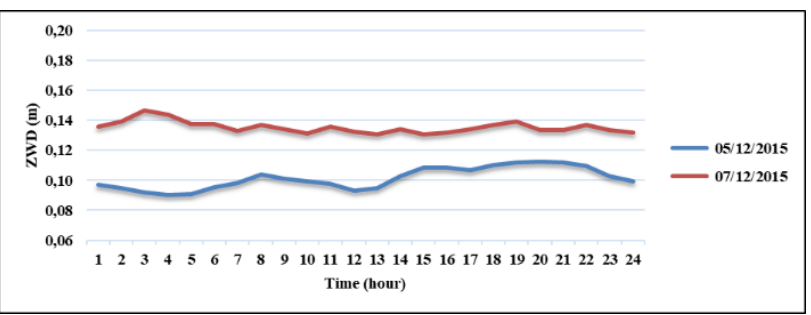

Figure $8 . \mathrm{PM}_{10}$ time series of Zonguldak.

A difference of $30 \mu \mathrm{g} / \mathrm{m}^{3}$ was observed at the average $\mathrm{PM}_{10}$ amount on 19-21 February 2015, whereas an average difference of $50 \mathrm{~mm}$ was calculated for the wet zenith delay values. Figure 9 shows ZWD values on 19-21 February 2015.

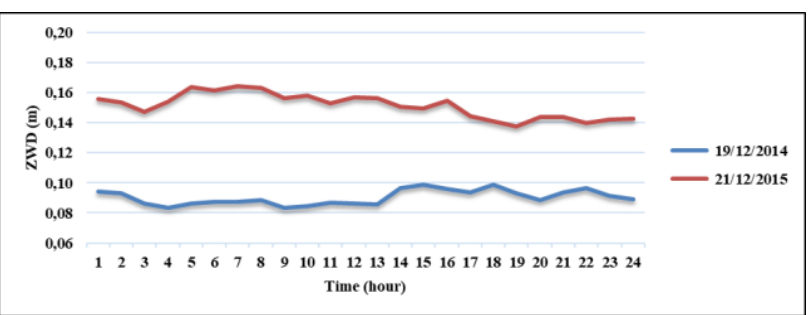

Figure 9. $\mathrm{PM}_{10}$ time series of Zonguldak.

A difference of $40 \mu \mathrm{g} / \mathrm{m}^{3}$ was observed at the average $\mathrm{PM}_{10}$ amount on 22-23 February 2015, whereas an average difference of $40 \mathrm{~mm}$ was calculated for the wet zenith delay values. Figure 10 shows ZWD values on 22-23 February 2015.

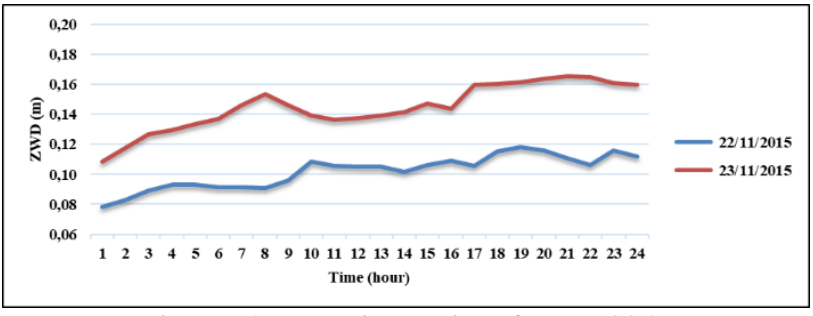

Figure 10. $\mathrm{PM}_{10}$ time series of Zonguldak.
In addition to these examples, samples selected from different days were examined, especially those with low $\mathrm{PM}_{10}$ differences of 1 to $10 \mu \mathrm{g} / \mathrm{m}^{3}$ were selected. The figures given below show graphs in which the days of little difference on $\mathrm{PM}_{10}$ values in the same meteorological conditions.

\begin{tabular}{|c|c|c|c|c|}
\hline Time & $\begin{array}{c}\text { Temperatur } \\
\mathrm{e} \\
\left({ }^{\circ} \mathrm{C}\right)\end{array}$ & $\begin{array}{c}\text { Pressur } \\
\mathrm{e} \\
(\mathrm{hPa})\end{array}$ & $\begin{array}{c}\text { Humidit } \\
\mathrm{y} \\
(\%)\end{array}$ & $\begin{array}{c}\mathrm{PM}_{10} \\
{\left[\mu \mathrm{g} / \mathrm{m}^{3}\right.} \\
]\end{array}$ \\
\hline $\begin{array}{c}15 / 12 / 201 \\
5\end{array}$ & 7.5 & 1011.7 & 79 & 101.2 \\
\hline $\begin{array}{c}16 / 12 / 201 \\
5\end{array}$ & 5.3 & 1011.1 & 83.5 & 104.2 \\
\hline $\begin{array}{c}06 / 11 / 201 \\
5\end{array}$ & 11.8 & 1006 & 90.4 & 82 \\
\hline $\begin{array}{c}07 / 11 / 201 \\
5\end{array}$ & 12.1 & 1008.6 & 95.7 & 84 \\
\hline $\begin{array}{c}08 / 02 / 201 \\
5\end{array}$ & 3.9 & 991 & 81.6 & 61 \\
\hline $\begin{array}{c}09 / 02 / 201 \\
5\end{array}$ & 3 & 991.4 & 78 & 66 \\
\hline
\end{tabular}

Table 3. Meteorological parameters of given days for PM10 comparison.

While the days indicated in Table 3 are examples of consecutive days with the same meteorological conditions, the values used are average values during the day. When the specified days were examined in detail, a difference of $3 \mu \mathrm{g} / \mathrm{m}^{3}$ was observed at the average $\mathrm{PM}_{10}$ value between 15-16 December 2015, whereas an average difference of $4 \mathrm{~mm}$ was calculated for the wet zenith delay values. Figure 11 shows ZWD values on 15-16 December 2015.

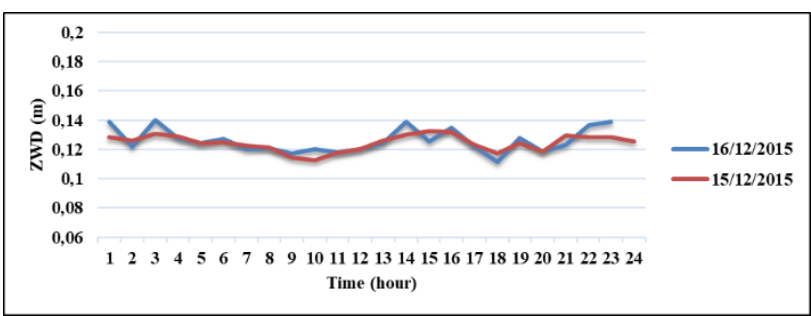

Figure 11. $\mathrm{PM}_{10}$ time series of Zonguldak.

A difference of $2 \mu \mathrm{g} / \mathrm{m}^{3}$ was observed at the average $\mathrm{PM}_{10}$ value between 06-07 November 2015, whereas an average difference of $4 \mathrm{~mm}$ was calculated for the wet zenith delay values. Figure 12 shows ZWD values on 06-07 November 2015.

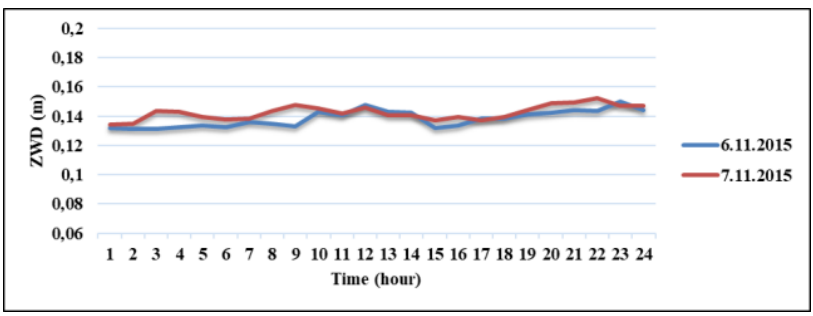

Figure 12. $\mathrm{PM}_{10}$ time series of Zonguldak.

A difference of $5 \mu \mathrm{g} / \mathrm{m}^{3}$ was observed at the average $\mathrm{PM}_{10}$ value between 08-09 February 2015, whereas an average difference of $2 \mathrm{~mm}$ was calculated for the wet zenith delay values. Figure 13 shows ZWD values on 08-09 February 2015. 


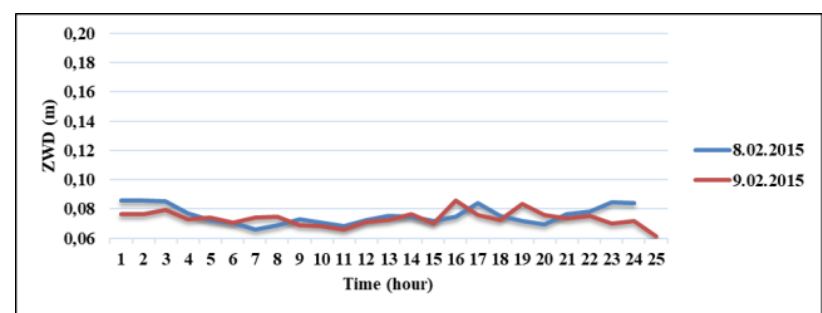

Figure 13. $\mathrm{PM}_{10}$ time series of Zonguldak.

\section{CONCLUSIONS}

In addition to the meteorological events that take place in the troposphere layer, air pollution originating from human influences also occurs. While describing the elements that cause air pollution, the factors that cause these elements are mentioned, both of which affect the human life. From these factors, the $\mathrm{PM}_{10}$ parameter forms the basis of this work.

The temperature, pressure and humidity values affecting the wet zenith delay are obtained from the General Directorate of Meteorology and the $\mathrm{PM}_{10}$ data obtained from the Zonguldak Air Quality Monitoring Station belong to the Ministry of Environment and Urban Planning. Data of ZONG GNSS station belongs to the TUSAGA-Active network obtained from the General Directorate of Land Registry and Cadastre. 2014-2015 data for the ZONG GNSS station processed with GAMIT/GlobK and GIPSY-OASIS II academic GNSS software. Results of the evaluations, the $\mathrm{PM}_{10}$ values were analyzed together with the changes of the ZWD values. Samples were given for days in which $\mathrm{PM}_{10}$ values were high and low on consecutive days with same meteorological conditions. The hourly ZWD changes of these days are observed to change at noon (11:00-13:00) and evening (18:00-21:00) during the day along with $\mathrm{PM}_{10}$ values. The reason for this difference is that the central heating boilers in Zonguldak city center are fed with coal twice a day at noon and evening hours.

The overall ZWD difference in days with same meteorological conditions and different $\mathrm{PM}_{10}$ values is changing at a range of 20$40 \mathrm{~mm}$ depending on the $\mathrm{PM}_{10}$ differences in the day, as shown in Figure 8-10. The stated ZWD value difference was $20 \mathrm{~mm}$ for a mean $50 \mu \mathrm{g} / \mathrm{m}^{3} \mathrm{PM}_{10}$ difference and $40 \mathrm{~mm}$ for a mean difference of $100 \mu \mathrm{g} / \mathrm{m}^{3} \mathrm{PM}_{10}$ in the day. The overall ZWD difference in days with same meteorological conditions and different $\mathrm{PM}_{10}$ values is changing at a range of 2-4 mm depending on the $\mathrm{PM}_{10}$ differences such as $1-5 \mu \mathrm{g} / \mathrm{m}^{3} \mathrm{PM}_{10}$ in the day, as shown in Figure 11-13. The result from these two comparisons is that the wet zenith delay that occurs on the days when the $\mathrm{PM}_{10}$ value is relatively high is greater than the wet zenith delay that occurs on days when the $\mathrm{PM}_{10}$ value is relatively low.

In addition to these differences in wet zenith delay and hence total zenith delay in the study area, the investigation of the effect of high $\mathrm{PM}_{10}$ values on positioning will also contribute to position accuracy studies. However, this study has shown that the effect of $\mathrm{PM}_{10}$ values on GNSS signals can be overlooked in study areas with low average $\mathrm{PM}_{10}$. In today's conditions, the use of natural gas for heating purposes is gradually increasing, but consumption of coal, especially from energy production, leads to an increase in $\mathrm{PM}_{10}$ values. This increase in the amount of $\mathrm{PM}_{10}$ should not be neglected, in addition to the effects on human health and visibility, as well as the precise positioning and other application of the GNSS. In future geodetic studies, it is recommended that the $\mathrm{PM}_{10}$ values in the study area should be investigated.

\section{ACKNOWLEDGEMENTS}

The authors are grateful to the organizations that provided the data, including General Command of Mapping (HGK) for TUSAGA-Active data, Turkish Met-Office (MGM) for meteorological data, Air Quality Monitoring Stations belonging to the Ministry of Environment and Urban Planning for PM $\mathrm{M}_{10}$ data and International GNSS Service (IGS) for daily RINEX and final products.

\section{REFERENCES}

Boehm, J., Werl, B., Schuh, H., 2006. Troposphere mapping functions for GPS and very long baseline interferometry from European Center for Medium-Range Weather Forecasts operational analysis data. J Geophys Res, 111: B02406. doi: 10.129/2005JB003629.

Gregorius, T., 1996. GIPSY-OASIS II How it Works.

Gurbuz, G., Jin, SG., and Mekik, C., 2015. Sensing Precipitable Water Vapour $(P W V)$ using GPS in Turkey: Validation and Variations, in S. Jin (Ed.), Satellite Positioning: Methods, Models and Applications, InTech-Publisher, Rijeka, Croatia, ISBN: 978-953-51-1738-4, pp.117-129.

Gurbuz, G., Jin, SG., 2016. Evaluation of ocean tide loading effects on GPS-estimated precipitable water vapour in Turkey. Geod. Geodyn, 7: 32-38. doi: 10.1016/j.geog.2015.12.008.

Herring, TA., King, RW., McClusky, SC., 2010. GAMIT Reference Manual Reference Manual GPS Analysis at MIT. Department of Earth, Atmospheric, and Planetary Sciences Institute of Technology, Massachusetts.

Jin, SG., Luo, OF., and Gleason, S., 2009. Characterization of diurnal cycles in ZTD from a decade of global GPS observations. J. Geodesy, 83(6), 537-545, doi: 10.1007/s00190-008-0264-3.

Robert, J., Lambach, MD., 2010. Outdoor Air Pollutants and Patient Health. American Family Physician, 81(2): 175-80.

Seinfeld, J., Pandis, H., 2006. Atmospheric chemistry and physics, from air pollution to climate change. 2nd edition, John Wiley and Sons Inc., New Jersey.

Zeydan, O., 2014. PM10 concentration distribution modeling in Zonguldak region, PhD. Thesis, Bulent Ecevit University, Zonguldak, pp: 184 . 